\title{
Sexual dysfunction in male patients with pulmonary tuberculosis
}

\author{
Ekaterina Kulchavenya ${ }^{1,2}$, MaximScherban ${ }^{2}$, Elena Brizhatyuk ${ }^{1}$, Alexander Osadchiy ${ }^{1}$ \\ ${ }^{1}$ Novosibirsk Research TB Institute, Novosibirsk, Russia, \\ ${ }^{2}$ Novosibirsk Medical University, Novosibirsk, Russia,
}

\section{Dear Editor,}

There were an estimated 8.8 million incident cases of tuberculosis (TB) globally in 2010, and 1.1 million deaths. ${ }^{1}$ Eighty percent of male patients with pulmonary TB are young men. ${ }^{2-6}$ It was proved that the tuberculous epididymitis was a cause of infertility 7,8 ; the development of infertility as a result of male genital tuberculosis was also reported. ${ }^{9-11}$ Infertility could sometimes be the first sign of male genital tuberculosis. ${ }^{12}$

To make clear the role of pulmonary tuberculosis in development of sexual dysfunction in men we conducted a comparative study of 105 newly diagnosed patients with pulmonary tuberculosis and 37 volunteers. Infiltrative pulmonary tuberculosis (IPTB) was diagnosed in 62 people, while cavernous pulmonary tuberculosis (CPTB) - in 43 people. Thirty-seven healthy volunteers were as a comparison group. All patients underwent routine clinical inspection, digital rectal examination and transrectal ultrasound prostate investigation, microscopic examination of prostatic secretion, semen analysis; all filled the questionnaires IIEF - International Index of Erectile Function and $\mathrm{NIH}-\mathrm{CPSI}$ - Chronic prostatitis symptoms index. All tests were estimated on base-line and after 3 and 6 months of standard chemotherapy with four anti-tuberculous drugs (isoniazid, rifampicin, streptomycin, pyrazinamide). Statistical analysis was done by Pearson criterion, Student $t$ test, and Wilcoxon test.

According to the results of questionnaires a significant disorder of all components of copulatory act and quality of life index was ascertained in both groups of patients with tuberculosis. The total score of the IIEF Scale in IPTB group, CPTB group and control was 24.7, 37.2 and 48.3 scores respectively $(p<0.0001)$. The lowest score in IPTB patients may be explained by more severe intoxication. The strongest correlations have been found between total score and intoxication (Pearson criterion/p-0.391/0.002; -0.332/0.008; $-0.317 / 0.01$, respectively). Self-assessment of sexual function was about the same in TB groups, but significantly differed from healthy volunteers (3.6; 3.8; 4.5 respectively).

Anti-TB therapy improved overall condition of TB patients, resolved intoxication as well as sexual function. Restore of libido was superior in IPTB patients than in patients with CPTB. In healthy volunteers the score was stable in 3 months (3.8); in IPTB group the score increased from 2.5 on the base-line to 3,0 in 3 months and 3.2 - in 6 months. In CPTB group initial score was lowest - 1.8; in 3 months it increased to 2.4 , and in 6 months - to 2.5. Improvement of self-estimated erectile function on IIEF Scale was in both TB groups, but it did not reach the parameters of healthy men (11.4). IPTB group on the base-line had 8.0 score, in 3 and 6 months it became 9.8 . CPTB group had the lowest score again - 5.1; after 3 months of the therapy it increased to 6.9 , but in 6 months it even a little decreased to 6.7.

The most significant changes in IPTB patients were in the first 3 months of the therapy: frequency of spontaneous erections increased, libido and sexual activity as well as quality of sexual life improved. In the next 3 months scores were stable but much lower than in healthy volunteers.

In CPTB patients first three months of the therapy were most effective too. All parameters of the sexual intercourse improved, but didn't rich the level of healthy volunteers $(p<0.0001)$. In six months of the anti-TB therapy the total score 
even decreased on some criteria (frequency of spontaneous erections, proportion of successful attempts of sexual intercourse, orgasm intensity).

TB patients have to take many medicines for a long time; anti-TB therapy negatively influences not only on mycobacterium tuberculosis, but also on human organism. Patients with pulmonary tuberculosis showed deterioration of all components of copulatory act, from sexual desire to orgasm, in spite of absence of any related diseases of genitourinary system. The degree of disorders in the group of patients with CPTB was significantly higher and it was correlated with a severity of intoxication syndrome.

Adequate anti-TB therapy could improve sexual function of a man with pulmonary tuberculosis by arresting the inflammatory TB process and reducing intoxication. Nevertheless even after 6 months sexual function in TB patients was worse than in healthy volunteers.
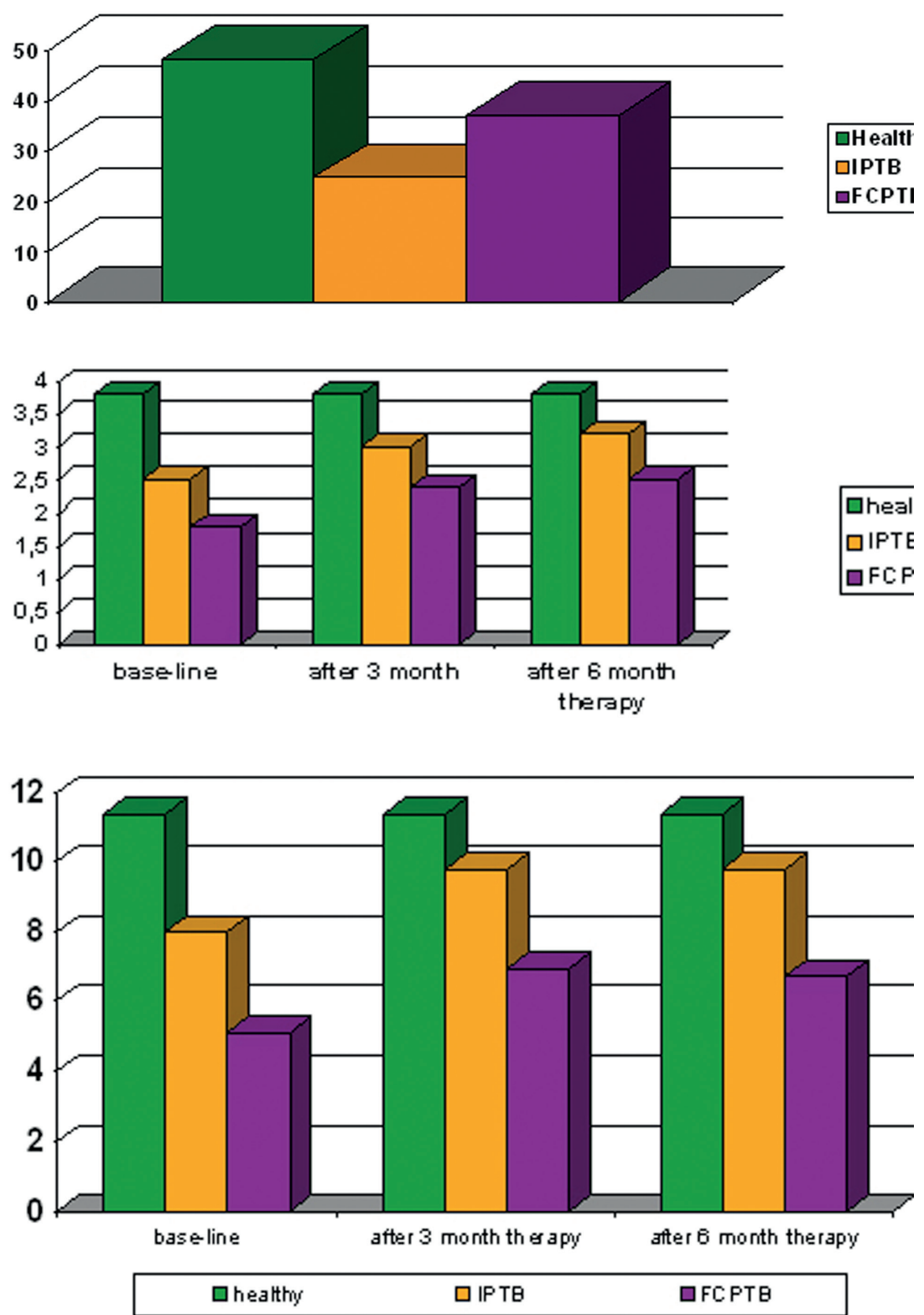

Diagram 1. The base-line of IIEF in patients with IPTB, FCPTB and Healthy People
Diagram 2. The Dynamics of Sexual Desire in Patients with pulmonary Tuberculosis
Diagram 3. The Dynamics of Erectile Function 


\section{REFERENCES}

1. The Global Plan to Stop TB, 2011-2015. Geneva, World Health Organization, 2010 (WHO/HTM/STB/2010.2).

2. Harries AD, Dye C. Tuberculosis. Ann Trop Med Parasitol 2006; 100: 415-431.

3. Tomioka H, Namba K. Development of antituberculous drugs: current status and future prospects. Kekkaku 2006: 81. N 12; 753-774.

4. Caminero JA. Treatment of multidrug-resistant tuberculosis: evidence and controversies Int J Tuberc Lung Dis 2006; 10:829-837.

5. Leung VK, Chu W, Lee VH, et al. Tuberculosis intestinal perforation during anti-tuberculosis treatment. Hong Kong Med J 2006; 12:313-315.

6. Mathew TA, Ovsyanikova TN, Shin SS, et al. Causes of death during tuberculosis treatment in Tomsk Oblast, Russia Int $\mathrm{J}$ Tuberc Lung Dis 2006; 10:857-863.
7. Colino M, Escandon S, Gomez G, et al. Tuberculous epididymitis caused by Mycobacterium bovis. Arch Esp Urol 2003; 56:175-178.

8. Fraietta R, Mori MM, De Oliveira JM, et al. Tuberculosis of seminal vesicles as a cause of aspermia. J Urol 2003; 169:1472.

9. Gorse GJ, Belshe RB. Male genital tuberculosis: a review of the literature with instructive case reports Rev Infect Dis 1985; $7:$ : 511-524.

10. Jimenez-Cruz JF, de Cabezon JS, Soler-Rosello A, et al. The spermiogram in urogenital tuberculosis. Andrologia 1979; 11: 67-70.

11. Sole-Balcells F. Tuberculosis and infertility in men. Eur Urol 1977; 3:129-131.

12. Lubbe J, Ruef C, Spirig W, et al. Infertility as the first symptom of male genitourinary tuberculosis. Urol Int 1996: 56:204-206. 